\title{
Determinants of Urban Poverty in Ethiopia: The Case of Jimma Town, South West Ethiopia
}

\author{
Tsegaw Zewdie AFESSA \\ Lecture, Department of Management, Mizan Tepi University, Ethiopia
}

\begin{abstract}
The objective of this study is to identify determinants of urban poverty in Jimma town. In order to meet the objectives of the study, cross sectional, descriptive and explanatory, research design applied. The sampling technique of the study used stratified and simple random sampling was employed to select households. Information has gathered a sample of 397 household heads were through primary and secondary data. A Logit model was employed and estimated based on the primary data, with the probability of a household being poor as a dependent variable and a set of demographic and socioeconomic variables as the explanatory parameters. By Considering total household consumption and dividing it by the household adult equivalent size, from sample of 397 surveyed household heads, the head count, poverty gap, and severity index of the survey obtained as $66 \%, 17.8 \%$ and 3.16 respectively. The finding revealed that variables that are positively correlated with the probability of being poor are gender, family size, employment/occupation and health/disease incidence of the household. Variables negatively correlated with probability of being poor are: income, educational level, and marital status, age of house hold, housing, house hold residence and saving. The major significance which affected significantly the incidences of poverty in the town are: education, income, age, saving, housing, gender, occupation, family size, previous residence, health and employment. The study concluded that most important determinants of urban poverty in the study area that plays a significant role in affecting incidence poverty are income, education and saving are the major implication to incidence of poverty. Study recommended that strong negative relationship between income, education, saving, housing, and residence with the probability of being poor point out that a need to consider government and non-government organization in designing strategy and policies targeted to curb urban poverty.
\end{abstract} Keywords: Urban poverty, Jimma Town, House hold-level, analysis

DOI: $10.7176 / \mathrm{CER} / 13-4-01$

Publication date:June $30^{\text {th }} 2021$

\section{Introduction}

Poverty has remained to be a worldwide problem and consequently it has been studied many times at global level and least developed countries, partly for their continuous fight against poverty. Africa is a continent gifted with enormous natural and human resources as well as great cultural, ecological and economic diversity, remains immature. The popular of the countries classified by the UN as a poor are in Africa. African nations typically fall toward the bottom of any list measuring economic position, such as income per capita or GDP per capita, despite a wealth of natural resources. Most Sub Sahara African countries suffer from military dictatorships, corruption, civil unrest and war, underdevelopment and deep poverty. Ethiopia is one of the world's poorest countries, where about 30 percent of the population lives under the poverty line, more than 12 million people are chronically or at least periodically food insecure (World Bank, 2015). Ethiopia as one of the developing countries in the world is the poorest of the poor by any standard (Esubalew, 2014). Poverty is widespread and multifaceted in Ethiopia. It affects a significant portion of its rural and urban population. Based on Estimates of international poverty lines, the incidence of USD I per day in the country is 26.3 Percent (World Bank, 2005). The Human Development Index (HDI) for 2014 (based on estimates of 2013), which takes life expectancy, adult literacy, primary schooling and per capita income is 0.435 which is low in comparison of Rwanda, Uganda and Sub- Saharan Africa and rank of Ethiopia is 173 out of the 177 countries.

According to the government reports the recent economic growth of Ethiopia is the highest not only in the long history of a country but also is the highest even by world standards. However, the data from the World Bank, shows poverty in Ethiopia fell from 56 percent in 2000 to 29.6 percent in 2017(more than 29 million people) were poor. According to UNDP (2014) quoted in Alemayehu and Addis (2015) in Ethiopia Despite the reduction in headcount poverty there has been an increase in the severity of poverty from 2.7 percent in $2004 / 5$ to 3.1 percent in 2010/11. This means that the poorest people were worse off in 2010/11 than they were in 2004/5. In Ethiopia the acceleration of urbanization has been accompanied by increase of urban poverty together with crowding, uneven distribution of development benefit and the change in the ecology of urban environment (Beshir 2017).

However, if managed proactively, the expansion of urban areas presents a huge opportunity to shift the structure and location of economic activity from rural agriculture to the larger and more diversified urban industrial and services sector.

The Ethiopian government has been Formulating and implementing various policy interventions and programs that are in one-way or another related with poverty reduction. Yet most efforts are biased towards rural 
areas. The influence of poverty is harmful both to the individual and the environment (Victor, 2011). The urban poor are families or individuals living below the poverty line who are illustrious by characteristic such as unemployment, lack of or inadequate access to basic service such as water, electricity, health and education and lack of nutrition food, shelter, clothing and access to information and new technologies needed for their survival (Leke 2011). Accordingly, in accordance with Ethiopia's existing growth and transformation program, the aim of this study was to develop determinants of poverty dealings, taking Jimma town of south west Ethiopia to accurately measure head count, incidence and severity of poverty and its contributing factors under the given socioeconomic and demographic condition.

While numerous studies have examined the incidence, tendency and multidimensional poverty the researcher motivated or spring boarded to re-examines the gap to narrow the previous work on urban poverty in jimma town. According to Jimma Town administration office report (2019) the social infrastructure in urban areas of this Town is insufficient and the economic futures of urban residents of the Town are characterized by poor condition. Urban dwellers of Jimma Town are vulnerable in different situation like involved in economic activities, such as government employment, urban agriculture and small scale trade which have low return (Tamirat M. \& Tegen D., 2018). Going to this existing fact it is straightforward to understand the existence of poverty in urban areas of Jimma Town.

Proper understanding of factors associated with urban poverty is a key to policies and practical steps that the government can take in ordered to eradicate urban poverty. Given these existing fact there is a need to examine urban poverty in Ethiopia. This study has a number of differences with the above previously conducted researches and tried to put criticize in perspective of variable difference, methodological differences, spatial and time difference of the respective study area and enhanced to improve these difference.

Hence Using data from sample 397 households collected from urban areas of Jimma Town by considering the fact that in this study area urban poverty is a growing problem requiring due attention.

\section{Methods}

\subsection{Study Area Description}

This study was conducted since 2020 at Jimma town which is the administrative and trading center and industry park of Jimma Zone. It is one of cash crop area which have eight sub town includes seventeen kebeles. Study also selected because of his prior knowledge and familiarity with the area. Jimma town is the capital of Jimma zone that is found $345 \mathrm{~km}$ far away from capital city of Ethiopia, Addis Ababa.

Jimma Zone is one of the 20 administrative zones in Oromia Regional State of Ethiopia, is alienated under 18 administrative districts or woredas. Jimma zone is one of the main coffee growing areas of Ethiopia and well gifted with natural resources contributing significantly to the national economy of the country (Jimma Zone Agricultural Bureau report, 2019). The study areas were selected due to the fact that in all sub town of jimma that was a capital of jimma zone, center of industrial park and the origin of rural to urban migration.

\subsection{Research Design}

This study was used mixed methods research approach. According to Saunders et.al (2009) cited in Deksiso (2017) mixed method approach is both qualitative and quantitative data collection and analysis methods are used. McGee (2001) quoted by Zewdu (2014) sates that the finding obtained from qualitative and quantitative methods will be less meaningful if they are not supported by or integrated with each other. In this regard, using of both quantitative and qualitative methods at the same time is more advisable (Teshome, 1998). Further, the study used descriptive research design and exploratory research design. In addition, the study was utilized cross-sectional survey designs study in the sense of that all relevant data was collect at a single point in time. The research also covered eight sub town (seventeen kebeles) of the town.

\subsubsection{Data Source and Type}

Households are the major units of analysis. This study was attended based on mainly primary data using a dedicated questionnaire that was filled by target groups with the help of trained enumerators who have experience and knowledge about the culture, language and ethics of the study areas' society. Primary source of data are the most helpful instruments for the researchers since the study was dedicated on the micro-level context of a country. A structured questionnaire was applied to collect information on household demographic compositions, level of education, health status, and living standard compositions. In addition, qualitative data were gathered via semistructured interviews and discussions which were prepared with selected stakeholders. Secondary sources were incorporated unpublished and published materials about features of multidimensional poverty.

\subsection{Sample size determination}

If a population from which a sample is to be drawn does not constitute a homogeneous group, stratified sampling technique were applied in order to obtain a representative sample (Abdi.K, 2015). Stratification is the process by which the population is divided into subgroups. By using this stratification process the study make the sample to 
be representative based on the geographical location we use to stratify the sample. The data collected by using these strata because in the study area there are 8 urban areas. Based on this condition sampling has been conducted separately in each subgroup or stratum.

Pertaining to how should sample to be selected from each stratum the study adopted the method of proportional allocation under which the size of sample from the different Strata are kept proportional to the size of strata. This means if $\mathbf{P i}$ represents proportion of population included in stratum $\mathrm{i}$ and $\mathrm{n}$ represents the total sample size, the number of elements selected from stratum $\mathbf{i}$ is $\mathbf{n} \mathbf{P i}$.

The sampling frame for simple random sampling, 95\% confidence level and 5\% precision level are used at criteria. To determine the sample size of the study area the researcher used Yamane's formula (1977) (as cited in Israel, 1992).

$n=\frac{N}{1+N(e)^{2}}$

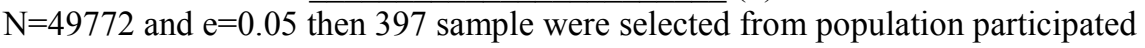

$\mathrm{n}=$ sample size.

$\mathrm{N}=$ the number of total populations in selected four sub town

$\mathrm{e}=$ the precision level (acceptable sampling error) $(0.05), 95 \%$ confidence intervals $\% .1=$ denotes the probability of events occurring.

Based on the above mechanism of selecting Sample from Strata:

$\mathrm{n}_{1}=\mathrm{nP}_{1}, \mathrm{n}_{2}=\mathrm{np}_{2}, \mathrm{n}_{3}=\mathrm{np}_{3} \ldots \ldots \ldots . \mathrm{n} 8=\mathrm{np} 8$. Where $(n)=$ sub town and $(p)=$ population in sub town.

\subsection{Method of Data Analysis}

Basically the analysis and presentation of the study is quantitative. In the first part, the research Use descriptive statistic s (percentages, ratios, means, standard deviations, Chi- squares. Significance intervals and t-test). These is analyzing and describe quantitatively by making use of Stata 13 Version and tables. In the second part econometric Issue s, more specifically, Logit model were adopted. Variables which play significant role s for the incidence of poverty in Jimma town have been analyzed through this model by making g use of econometric issues.

Study was employed different software to determine the coefficients of the determinants odds, odds ratio, and marginal effects and test the statistical significance relationships between the determinants and the dependent variable (urban poverty).

\subsection{Model Specification}

In addition to descriptive analysis econometric models was used to analyze determinants of urban poverty in the study area. The data concerning the issue of poverty was collected by interview and analyzed by converting the monthly expenditure of house hold in study area into per day. Following this, the amount of expenditure per day earned by house hold in the study area was recorded. Then after, the results obtained, it was compared with the poverty line or cut off point that was identified by different national and international organization. Poverty line is a cut of point that distinguishes poor and non-poor households or it can be defined as level of consumption (or income) needed for a household to escape poverty (Teferi, 2017).

According to World Bank the global poverty line has to be periodically updated to reflect the socio economic changes that affect cost of living. As of October 2015, World Bank state the new global line will be updated to $\$ 1.90$. Respondents with expenditure level of below this minimum requirement were categorized as poor and those respondents with above the cut off were considered as non-poor. The next steps were identification of variables that are assumed to have association with poverty at a respondent level. After data collected on the variables associated with urban poverty it was organized, edited and analyzed using Stata version 13.

As the dependent variable has a dichotomous nature (poor or non-poor), a binary logistic regression used, where the estimated probabilities lie between logical limit 0 and 1 (Gujarati, 1995). Accordingly, variables assumed to have influence on the probability of being poor or non-poor in different contexts were tested in the model. The general description of the model and its application is described below. The study was employed Logistic regression model (Equation 1) with the dependent variable (the status of respondents regarding to poverty) being a binary variable having a value of one if a respondent will be found poor, and a value of zero otherwise:

$p i=E\left(y=\frac{1}{x i}\right)=\frac{1}{1+e^{-z i}}={\frac{e}{1+e^{z i}}}^{z i}$

Where $\mathrm{e}$ is an exponential term $\mathrm{Pi}$ is the probability of respondent being poor. $\mathrm{Y}$ is the observed status of a respondent regarding to poverty. $\mathrm{Xi}$ is the respondent set of explanatory variables $\mathrm{Zi}$ is a function of n-explanatory variables $(\mathrm{Xi})$ which can be expressed in linear form as:

$Z i=\beta 0+\beta 1 X 1+\beta 2 X 2+\beta 3 X 3+\beta 4 X 4+-----+\beta n X n$

From Equation 1, the probability of a respondents being non poor is given by $(1-P i)$ which can be written as: 


$$
\begin{aligned}
& 1-p i=1-\frac{1}{1+e^{-z i}}=\frac{1+e^{-z i}-1}{1+e^{-z i}}=\frac{e^{-z i}}{1+e^{-z i}} \\
& \text { Therefore, the odds ratio } \frac{p i}{(1-p i)} \text { is given by }
\end{aligned}
$$

$\frac{p i}{(1-p i)}=\frac{1+e^{z i}}{1+e^{-z i}}=e^{z i}$

Now, $\frac{p i}{(1-p i)}$

Is the odds ratio in favor of being poor and It is simply the ratio of the probability that a respondent would be poor (Pi) to the probability that a respondent would be non-poor (1-Pi). According to Gujarati, 1995 if we take the natural $\log$ of the above equation (equation 3 ) we obtain a very interesting result.

$\boldsymbol{L i}=\boldsymbol{l n}\left(\frac{p i}{1-p i}\right)=\boldsymbol{z i}$---

Where, $L i$ is the log of odds ratio which is not only linear in variables but also (from the estimation view point) linear in parameter. The above equation is logit and hence the name logit model for models likes the above model. If the disturbance term is introduced, the Logistic regression model in Equation 4 is represented below:

$Z i=\beta 0+\beta 1 X 1+\beta 2 X 2+\beta 3 X 3+\beta 4 X 4+-----+\beta n X n+£----------E q u a t i o n ~ 5$

In Equation 5 , the terms $\beta \mathrm{i}$ are parameters to be estimated, and $\mathrm{X} 1$ to $\mathrm{Xn}$ are explanatory variables such as: the gender of the family head, family size of the household, marital status of household head, education of the household head, occupation of household head and other variable associated with urban poverty. In this logit model the slope coefficient of a variable gives the change in the log of odds ratio in favor of being poor associated with a unit change in that variables, holding all other variable constant. But in the logit model the rate of change in the probability of an event happening is given by

$p i(1-p i) \beta i$ Where $\beta i$ is the (partial regression) coefficient of the "ith" repressor (Gujarati, 2004). Depend on this in our case the rate of change in the probability of being poor is given by $p i(1-p i) \beta i$.

$\frac{\partial p i}{\partial x i}=\boldsymbol{p i}(1-p i) \beta \boldsymbol{i}$-----------------------------------------------------------------------Equation 6

This equation shows us the marginal effects of each explanatory variable on respondent being poor can be calculated from the estimated Logistic regression model.

\subsection{Descriptions of explanatory variable and expected signs}

In econometric model two main variables were explored: the dependent variable (in this case the probability of being poor) and independent variables (the determinants of urban poverty in the study area). According to economic literatures on the issues of urban poverty a number of explanatory variables could determine urban poverty directly as well as indirectly, due to this reason only few determinants of urban poverty in the study area would be analyzed. In many econometric models the dependent variable and independent variables can be cause and effect of the other, but in our case we assumed a one direction relationship between both variables and the dependent variable (the probability of being poor) is determined by the explanatory variables. At the all in this model the dependent variable is categorized as poor and non-poor and the model were estimated by using Maximum likelihood technique. In this study identifying determinants of urban poverty requires a clear definition of poverty. The World Bank defines poverty as a pronounced deprivation in well-being. However, this definition leads to the important question of what ,well-beinge and how it should be measured. In economic literatures a range of approaches that address this issue exist. This study was depending on the non- welfares' approaches which bases the assessment of well-being on the attainment of certain basic achievements those are related to income, such as food, clothing and shelter.

Depend on the above context the next section gives some explanation for explanatory variables and provided hypothesis statement.

Household Family Size (HHFS): Family size affects the level of income required for house hold to escape from poverty. Increment in family size would imply decline in the level of income or another indicator of welfare essential to escape from poverty. In this study it is hypothesized that the increase in family size expected to raise the chance of being under poverty line.

Education of Household Head (EHH): The education of the house hold head also expected to have an impact on the chance of being poor or not. In principle the literate house hold expected to have more chance to escape from poverty.

The gender of house hold head(GHH): As the sex of hose hold head changed from male to female or vice versa it may move to above poverty line or below poverty line. The sex of household head takes a binary value. If the sex of household head is Male, it takes 1 and 0 for otherwise. This shows the study was taken female as a base group.

Marital status: Marital status is identified as one of important demographic factors that affect the probability that 
a household would be poor. This explanatory variable takes a binary value and married household head takes 1 and 0 for otherwise. In light of this it was hypothesized that being married household head has less or high probability of being poor than others this means this study was expected being married household head may have negative or positive effect on the probability of being poor.

Household Health (HHH): In principle household with poor health condition would have a poor living standard. Most of time when household head get sick, all member of the household faces different problems and one of among others is poverty. In this study health is, expected to play a negative role in urban poverty. Households with frequent patient members take value of 1,0 otherwise

Household Head Occupation (OCHH): this explanatory variable refers type of occupation that the household head is engaged in. To see the role of household heads work in effecting poverty status, the study was used the head work as a binary. If a Household heads does any work for salary it takes value 1,0 otherwise

Age of head of household (AHH): Age of head of household is measure in complete years. In principle people in productive age group is believed to earn more income than others. The study was treat age of household as continues variable. In economic literatures there is no clear relationship between poverty and age of the household head. Based on this it was hypothesized age of household head may have negative or positive effect on the probability of being poor.

Dependency Ratio (DRHH): The dependency ratio is defined as the ratio of number of members $(<18$ years and $>64$ years) to household size and treated as a continuous variable. The study hypothesizes that as the number of dependency ratio increase in a house hold the probability of being poor is increases.

Income of household head (IHH): is a continuous variable, which include a total monthly income of the households. Theoretically the household with higher level of Income would have high probability to escape from poverty. In this study the level of income is expected to have inverse direction with the probability of being poor. House Ownership (HOWN): Ownership of house can be taken as proxy for wealth. It is a dummy variable 1 if the respondent has house, 0 otherwise. In this study it is expected that household who own their house would have a low probability to being under poverty line than those who are paying rent.

Saving of household: In developing countries like Ethiopia saving are low, because of low income. In principle household with practice of saving have better chance to escape from poverty. This means households of non-saver faced the incidence of poverty more than saver. This variable is a dummy variable 1 if the respondent is saver, 0 otherwise. In this study it is expected the probability to be poor is less for saver household.

Previous residence: Migration from rural areas and other city is one of the most important causes of growth and change in a demographic and socio economic characteristics of a given urban population. This explanatory variable is a dummy variable and if households are endogenous households it takes 1 and 0 other wise. In this study it is hypothesized that incidence of poverty is more widespread among those migrants than endogenous

\subsection{Method of Welfare Measure}

This study used consumption expenditure as an indicator of welfare in general and cost of basic needs (CBN) approach in particular to classify household in the study area as a poor and non-poor. The rationale behind using consumption expenditure as indicator of welfare is that in developing countries like Ethiopia income is hard to measure (much of its comes from self-employment), while expenditure is more straight forward and hence easier to estimate. In the economic literature on welfare indicator, the second candidate after consumption expenditure is income. This study was not used income as an indicator of welfare due to the following reasons: income is likely to be underreported; it may be affecting by short term fluctuations, some parts of income are hard to observe (for example informal sector income and self-employment income), link between income and welfare is not always clear and reporting period might not capture the average income of the household (Ravallion, 1993 cited in Garza. $2001)$.

\subsection{Equivalence scales}

In economic literatures a series of issues arise when calculating the aggregate, related to both the size and composition of households. In this study some forms of normalization were used to allow comparison of households, in light of both size and composition. If not adjusted one might overestimate the poverty of households with numerous children and underestimate that of household with few children (Melese, Solomon and Kebede, 2017). This study was used equivalence scale that takes both household size and household composition into account to adjust the consumption or expenditure aggregate for household composition in order to compare households and to compare the aggregate with the poverty line. An equivalence scale that was used by this study looks like: $\mathbf{N}$ Equivalent Adult $=\mathbf{1}+(\mathbf{N}$ Adult $-\mathbf{1}) * \mathbf{0 . 7}+(\mathbf{N}$ child under $\mathbf{1 5} \mathbf{0 . 5})$, then by dividing the total consumption expenditure by the number of adult equivalent the study where used the result to compare households and to compare the aggregates with poverty line. 


\section{Results and Discussion}

\subsection{Determinants of Poverty in the study area}

According to Melese (2017) the importance of this assumption is that, since we use a household level analysis, we can easily classify households as poor and non-poor by taking their total household consumption and dividing it by the household adult equivalent size.

In The absence of an invariable and updated national poverty line, a poverty line of meeting 1.9 USA dollars per person per day a value which is currently used by World Bank as a poverty line for less developed countries such as Ethiopia is used for the purpose of this study. That is, an urban household is categorized as poor if her/his daily total expenditure per adult family size is falls below 62.32 ETB (at time of data collection the official exchange rate was $32.8 \mathrm{ETB} / 1 \mathrm{USD}$ ). Based on this poverty line the summary results related to level of poverty, its depth and severity in the study area are given below.

$\sum_{i=1}^{397} y i / \sum_{i=1}^{397} A L i>62.32=133$ households above poverty line

$\sum_{i=1}^{397} y i / \sum_{i=1}^{397} A L i<62.32=264$ households below poverty line

As introduced earlier under methodology part logistic regression is used to examine relationship between a dichotomous dependent variable and independent variable of dummy and continuous form. In this study logistic regression combines the explanatory variables to estimate the probability of the household falling below poverty line or not. Therefore urban poverty is as dependent variable while demographic and socioeconomic variables are as explanatory variable.

The estimations appear in the following table.

Table 3.1 Determinants of poverty in the study area

\begin{tabular}{|l|l|l|l|}
\hline Variable & Coefficients & P-value & Marginal effects dy/dx \\
\hline AHH & -0.2692378 & $0.019^{* *}$ & -0.0019799 \\
\hline GHH & 4.061202 & $0.011^{* *}$ & 0.0298655 \\
\hline MSHH & -5.66769 & $0.016^{* *}$ & -0.0416794 \\
\hline EHH & -0.5286633 & $0.000^{*}$ & -0.0038877 \\
\hline PRHH & -5.623682 & $0.026^{* *}$ & -0.0413558 \\
\hline HHFS & 4.1485 & $0.063^{* * *}$ & 0.0305075 \\
\hline OCHH & 3.093754 & $0.062^{* * *}$ & 0.022751 \\
\hline SHH & -5.663551 & $0.018^{* *}$ & -0.041649 \\
\hline DRHH & 10.43644 & 0.346 & 0.0767481 \\
\hline IHH & -0.0032591 & $0.002^{*}$ & -0.000024 \\
\hline HHH & 2.735116 & $0.037^{* *}$ & 0.0201137 \\
\hline HOWN & -5.947856 & $0.018^{* *}$ & -0.0437397 \\
\hline Constant & 18.39545 & $0.002^{*}$ & \\
\hline
\end{tabular}

Source: Authors' estimations, 2020

The estimated results for logit model of this study demonstrated that from a total of 12 variables 11 variables are statistically significant at 1 percent, 5 percent and 10 percent significance level. The coefficient associated with the age of household implies that the probability of being poor is negatively affected by age of household head in this model this variable is significant at 5 percent level of significance. Other thing remains constant as age of household increases by one year the probability of households falling into poverty decreases by around $0.2 \%$. This finding also supported by (M. Tariq and M. Malik,2015). The sign of the coefficient of gender of household showed a positive effect on the probability of household falling into poverty and it is statistically significant at 5 percent significance level. This showed the probability of a household being poor is lower in female headed households than male headed. In economic literatures the prevalence of poverty in female headed households are higher because of discrimination in favor of male in the labor market. In the study area if the household is headed by female, the probability of such household falling into poverty decreases by $2.98 \%$. Study also supported by (M. Tariq and M. Malik,2015). However, in this study the sign of the coefficient of this variable showed a negative relationship between marital status and the probability of household falling into poverty and it is statistically significant at 5 percent significance level. Married household heads are $4.1 \%$ more likely to escape from poverty in comparison with single, divorced, and widowed households keeping other factors constant. Education of household head is largely contributed to ensure better living condition of household. This variable affects the probability to be poor negatively and significantly at 1 percent significance level. The negatively relationship indicates that literate households have less probability to be poor than illiterate household. Other thing remains constant if education year of the household increases by one year the probability of household falling into poverty reduces by $0.388 \%$, this is due to educated household head plays a significant role in shaping household members 
and educated household head have opportunities to get employments with good income. The finding of this study was found consistent with what had been found by (Mohammed, 2017) and (Esubalew, 2006). Household family size affects the probability of being poor positively and significant at 10 percent significant level. As family size increases by one member the probability of a household being poor increases by $3 \%$, other thing remains constant. This finding also supported by (Muhedin M.,2015). Occupation status or employment affects the probability of being poor positively and significant at 10 percent. The result showed that being employed either in government or non-government sector are lower escape poverty than involved under trade and manufacturing enterprise. As employment house hold increase by one unit the probability of being poor increase by $2.27 \%$, other things remain constant. This reflects that trade activities have the highest probability of decreasing poverty followed by manufacturing (SisayT. and Minyahil H.,2018). The sign of the coefficients of saving in the regression results showed a negative relationship with the probability that of falling into poverty. Households with practices of saving have better probability to escape poverty. This result of a variable is significant at 5 percent significance level and the implication is households with practice of saving are $4.1 \%$ less likely to be poor than non-savers keeping other thing constant. Households with practice of saving and credit utilization have better chance to escape from poverty because they have good ground to invest on profitable businesses and coping short term market shocks (Mohamed B.,2017). Results of logistic regression revealed that the coefficient for the income is found to be negative and statistically significant at $1 \%$ significance level. As household's income increase by 1 birr, the probability of household falling into poverty decreases by $0.0024 \%$. Because of the households are engaging in trade and selfemployed revenue generation. studies confirm this result such as (Esubalew A.,2006). The marginal effect of disease incidence implies that if the household have a frequent sick, the probability of such household falling into poverty increase by $2 \%$ relative those who are not. Most studies confirm this result such as Sintayehu F. (2012) and Esubalew A. (2006). The marginal effect of house ownership implies that if the household have a house, the probability of such household falling into poverty decreases by $4.3 \%$ relative to household who does not have a house. Keeping other factors constant endogenous households are $4.1 \%$ more likely to escape from poverty in comparisons with households comes from rural and urban areas. study also supported by (M. Tariq and M. Malik,2015). Living in rural areas results a positive and significant effect on the issue of multidimensional poverty relative to living in urban areas (SisayT. and Minyahil H., 2018).

\subsection{Severity and Incidence of Poverty}

The result of the following table shows that majority of the households are grossly deprived with regards to dignified and improved standard of living.

The earliest and perhaps the most commonly used statistics to measure the extent of poverty and to aggregate the information on individuals ${ }^{\text {ee }}$ welfare are Head Count Index (P0), Poverty Gap index (P1) and Severity Index (P2). Depend on this fact the study was used those indices of poverty as follow.

I. Head count index (P0): This index gives the proportion of sample households who are poor.

$\mathrm{P} 0=\mathrm{Np} / \mathrm{N}=$ where $\mathrm{Np}$ is total number of poor house hold and $\mathrm{N}$ is total sample size. $\mathrm{P} 0=\mathrm{Np} / \mathrm{N}=264 / 397=0.6649$

The explanation for the information is clear-cut: in the study area 66 percent of people are poor. According to the different aspect of poor indication, this means that they are in sharp or acute poverty.

II. Poverty Gap Index (P1): This index measures the depth of poverty better than $\mathrm{P} 0$, it is insensitive to the number of individuals below the poverty line and to the transfer of income among the poor.

$$
P(1)=1 / N \sum_{i=1}^{q}\left(\frac{\mathrm{Gi}}{\mathrm{Z}}\right)
$$

$$
\mathrm{Gi}=\left\{\begin{array}{cc}
Z-Y i, \text { if the individual is poor } \\
0 & \text { otherwise }
\end{array}\right.
$$

Where; $\mathrm{Yi}$ is Consumption expenditure or of the poor and $\mathrm{Z}$ is Poverty line.

$P(1)=1 / 397(70.8)=0.178$

This index is adding up the extent to which individual on average fall below poverty line and expresses it as a percentage of the poverty.

The result implied that also indicates that on average the poor are deprived in 17 percent of the weighted indicators. The different aspect of poor indicator reflects the group of the population that is poor accustomed by the intensity of the deprivation suffered. The average poor person is underprivileged in 17.8 percent of the weighted indicators; thus, the intensity is 17.8 percent.

III. Poverty severity Index (P2): It is a measure of poverty that takes into account inequality among poor.

$$
P(2)=1 / N \sum_{i=1}^{q}\left(\frac{\mathrm{Gi}}{\mathrm{Z}}\right)^{2}
$$




$$
\mathrm{Gi}=\left\{\begin{array}{cc}
Z-Y i, \text { if the individual is poor } \\
0 & \text { otherwise }
\end{array}\right.
$$

Where; $\mathrm{Yi}$ is Consumption expenditure or of the poor and $\mathrm{Z}$ is Poverty line

$$
P(2)=1 / 397(70.8)=(0.17) 2=0.0316 \text {. }
$$

Meanwhile the society of the study area on average deprived in 17 percent of the different indicators, the society is deprived in 3.16 percent of the total potential deprivations it could experience taken as a whole.

\section{Conclusion and Recommendation}

The aim of this study was to assess the determinants of urban poverty in Jimma town so as to help proper understanding of factors associated with urban poverty which is a key to policies and practical steps that the government can take in ordered to curb urban poverty. Based on this condition the finding of this study shows that in the study area the proportion of people who are under poverty line are 66.5 percent This means from the total 397 surveyed households 264 of them are found below poverty line. The incidence of poverty among the sampled households showed that $66.5 \%, 17.8 \%$ and $3.16 \%$, for headcount index, poverty gap index, and poverty severity index respectively. This results call for urgent intervention to curb the level of poverty. Explanatory Variables, which were hypothesized as determinants of urban poverty in the town, were selected and analyzed. These variables were household family size, education of household head, gender of household head, household health, and household head occupation, age of head of household, dependency ratio, income of household head, saving of household, house ownership, previous residence and marital status of household head. The relationship between these variables and poverty in the study area were analyzed through descriptive statistics. A Logit regression model was employed to examine quantitatively the relationship between these determinants and poverty. The data were subjected to analyses by using different software's such as Stata version 13. The specific statistic used includes percentage, mean, and standard deviation in descriptive statics and Logit model of regression in the econometric analysis.

The findings of logit maximum likelihood estimation of the study showed from total of 12 explanatory variables only 11 variables are statistically significant at 1 percent, 5 percent and 10 percent significance level. These variables are household family size, education of household head, gender of household head, age of head of household, house hold saving, income of household head, house ownership, previous residence and marital status of household hold, house hold health and house hold occupation.

Based on both descriptive and econometric method of analysis furthermore by using the result of marginal effect the study was explained the effect on the dependent variable that results from changing on independent variable by a small amount. The most important determinants of urban poverty in the study area that plays a significant role in affecting incidence poverty are income of households. As in line with other studies it has been found that the coefficient for the income is negative and statistically significant at $5 \%$ significance. The coefficient associated with the age of household implies that the probability of being poor is negatively affected by age of household head in this model this variable is significant at 5 percent level of significance and the marginal effect of this variable is 0.2 percent. Relationship between marital status and the probability of household falling into poverty is negative and it is statistically significant at 5 percent significance level. Married household heads are 4.1 percent more likely to escape from poverty in comparison with single, divorced, and widowed households keeping other factors constant. Household family size affects the probability of being poor positively and significant at 1 percent significant level. Other factors remain constant as family size increases by one member the probability that a household would be poor increases by 3 percent. Furthermore, the result of the study showed households with practices of saving have better probability to escape poverty. Households with practice of saving are 4.1 percent less likely to be poor than non-savers keeping other factors constant. This result of a variable is significant at 5 percent significance level. In the study area household who own house have a less probability to be poor. The probability of such household falling into poverty decreases by 4.3 percent relative to household who does not have a house and the result is significant at 5 percent. The sign of the coefficient of gender of household head is statistically significant at 5 percent significance level. The probability that a household would poor is lower for female headed households than male headed and if the household is headed by female, the probability of such household falling into poverty decreases by 2.9 percent. In the study area previous residence of household is negatively affect the probability of being poor and it is significant at 5 percent significance level. Keeping other factors constant endogenous households are 4.1 percent more likely to escape from poverty in comparisons with households comes from rural and urban areas. Finally, the main conclusion of the study is that the incidence of poverty is widespread in the study area. This problem is call for urgent interventions aimed at dropping this incidence of poverty. Depend on their effect and urgency to curbing poverty factors associated with urban poverty can be used as a key to policies and practical steps that the government and non-government organization can take in ordered to curb urban poverty. This study has attempted to examine the determinants of urban poverty with defined scope however a lot remained to be unanswered. To provide basic information on the determinants of urban poverty, the political, social, natural and environmental dimensions, role of urban agriculture in reducing 
urban poverty, specific characteristics that make urban residents more vulnerable to poverty demands future researchers ${ }^{e e}$ attention. Thus poverty alleviation policies that based on those variables should be key ingredients of a poverty reduction strategy and the targeted groups should involve in any development efforts that could address the problem identified. In the framework of the population under study, it is clear that for anti-multidimensional poverty schemes to be well-targeted and hence more efficient, policy or program devise and interventions ought to focus on addressing the specific variables that are found to be most significant in determining the level of household multi-dimensional poverty. In particular, such interventions should clearly target the needs of urban dwellers, which are relatively more underprivileged in terms of multidimensional factors. Improving wealth of urban household can be achieved by improving access to resource and implementing policies that demarcates the right to these possessions. Education and job creation must get more attention to bring sustainable change on multidimensional poverty reduction campaign.

\section{Reference}

Abbi, Kedir and Andrew (2013): Chronic Poverty in Urban Ethiopia: Panel Data Evidence.

Abbi, Mamo and Kedir (2015): Understanding urban chronic poverty in Ethiopia: crossing the qualitative and quantitative divide.

Aaron Maasho (2007): Assessing the Urban population in Ethiopia:Nazret.com.

Alehegn. T (2013): Determinants of urban poverty in Debre Markos, Ethiopia: a household level analysis.

Ayalneh , Konrad, Hagedorn and Benedikt (2012): Why does poverty persist in rural Ethiopia.

Bigsten,A ;Abebe ,S; \&Mekonnen .T (2002). Change in Welfare and Poverty: An Application Of Stochasti c Dominance Criteria; Ethiopian Journal of Economics, Special Issue, 8 (I): 2 1-2 6.)

Ben C. Arimah (2010): The Face of Urban Poverty Explaining the Prevalence of Shantytowns in Developing Countries.

Bogale , A and Hagedorn , K (2004). Poverty Profile and Livelihood diversification in rural

Deksiso, L. (2017, May). Socio-Economic Effects Of Rural-Urban Migrant Youths In Addis Ketema Sub-City. Addis Ababa, Federal State, Ethiopia: Ignou.

Dessa legn R. Aklilu K. (2002). Livelihood In security Among Urban households in Ethiopia

Esubalew T. (2014): An Investigation of Macroeconomic determinants of the domestic Private Investment Evidence from East Africa.

Ethiopia proceedings of the First International Conference on the Ethiopian Economy, Ethiopian Economic Association: Lisan printing press. Addis Ababa.. Forum for Social Studies. Image printing Press. Addis Ababa.

Ethiopian Economic Association (2004/05) Report on the Ethiopian Economy ' 01 IV. Rohobot Printe rs. Addis Ababa. Ethiopia.

Ethiopian Economic Association (2006). Proceedings of the third International Conference on the Ethiopian Economy. Printed in Digital Computer Graphic s. Add is Ababa. Ethiopia

Eyob.F (2015): Measuring the attributes of poverty and its "residual persistence" in Eritrea.

Foster, J., J. Greer, E. Thorbecke. (1984): “A class of decomposable poverty measures.” Econometrica 52, no. 3: 761-765.

Fitsum.T (2011): poverty in Addis Ababa: a comparison of female and male headed households

Kedir. A and McKay, A (2003). Chronic Poverty in International Conference on "Staying Poor: Policy". Manchester, UK, 7 - 9 April 2003. Urban Ethiopia, paper Chronic Poverty and prepared for Development.

Leke Oduwaye,Victor Ilechukwu, Omoayena Yadua (2011) : Socio-Economic Determinants of Urban Poor Housing Types in Makoko Area, Lagos.

Meron A. (2002). Gender Dimensions of Urban Poverty in Ethiopia: The case of three kehele.1 In Addis Ababa. Forum for Social Studies.

Mekonen T. et al (2002): Growth and Poverty Reduction in Ethiopia: Evidence from Household Panel Surveys, Addis Ababa Ethiopia.

Mek, et al (2017): The Determinants of Urban Household Poverty in Malaysia

Meron Assefa (2003): Female heeded household and poverty in urban Ethiopia

Mduduzi, Biyase and Talent (2017): An Empirical Analysis of the Determinants of poverty And house hold welfare in South Africa.

MoFED (2002). Ethiopia. Sustainable Development and Poverty Reduction Program (Draft) Ministry of Finance and Economic Development. Addis Ababa.

Mok, T. Gan1 and A. Sanyal (2016): The Determinants of Urban Household Poverty in Malaysia.

Muhdin Muhamedhussien (2015): Determinants of rural income poverty In Ethiopia: case study Of Villages of Dodolla District.

Mulat,fantu and ,Tadele (2011) growth, employment, poverty and policies in Ethiopia: An empirical investigation. Mohammed Beshir Mohammed (2017): Measurement and Determinants of Urban Poverty in Case of Southern 
Nations, Nationalities, and Peoples ${ }^{e e}$ Region (SNNPR), Ethiopia.

Saidatulakmal1 and Madiha Riaz (2012): Demographic Analysis of Poverty: Rural-Urban Nexus.

Sissay and Minyahil (2020): Multidimensional Poverty analysis: In case of Jimma zone, south west Ethiopia.

Sintayehu Fekadu et al. (2012): Epilepsy, poverty and early under-nutrition in rural Ethiopia.

Teshome kebede and M.K (2014): Determinants of Poverty in Ethiopia.

Tamirat and Tegegn (2018): Livelihood in Dilapidated neighborhoods of Jimma city:the effort of poor urban Dwellers to survive.

Tarik Majeed and M.Nauman (2020): Determinants of Household poverty: empirical evidence From Pakistan.

Teferi et al., (2017): Fishing and poverty levels around Lake Victoria in kenya: Socio-economics of the Lake Victoria fisheries.

Tesfaye A. (200 4). Analysis of Urban Poverty in Ethiopia. Discipline of Economics. University Of Sydney, Australia. Working Paper.

Tesfaye, Alemayehu and Gebremedhin (2013): The Analysis of Urban Poverty in Ethiopia.

Tesfaye . K (2 004). The Economics of Education. Proceedings of the First International Conference on the Ethiopian Economy, Ethiopian Economic Association, Lesan Printing Press. Addis Ababa.

United nation development program (2016): Human development report for everyone.

World Bank Monitoring report (2015): definition and measurement of poverty analysis.in the case of Global monitoring report.

World Bank (2001). World Development Report 200/01: Attacking Poverty. Oxford University Press.

World bank, (2002), Development and Poverty Profile of Ethiopia. Addis Ababa, Ethiopia.

Yared M. (2005). Remittances and Poverty Persistence in Urban Ethiopia. MSc Thesis In Economic Policy and Analysis. Add is Ababa University (unpublished).

Yonas, Gunnar and Jesper (2012): The persistence of subjective Poverty in urban Ethiopia.

Zewdu, G. (2014, May). The Impact of Migration and Remittance On Home Communities In Ethiopia. 